\title{
Cultura e experiência nos romances de Raymond Williams
}

\section{Culture and experience on Raymond Williams' novels}

https://doi.org/10.34112/2317-0972a2019v37n77p17-32

Alexandro Henrique Paixão ${ }^{1}$

José Ricardo Beltramini de Melo ${ }^{2}$

Mariana Carvalho Murad ${ }^{3}$

RESUMO: Este trabalho, que combina sociologia da literatura e psicanálise, tem como enfoque discutir alguns elementos constitutivos da narrativa ficcional de Raymond Williams, tais como: as dimensões temporais (passado, presente e futuro); a transmissão de experiências na esfera familiar; a conexão entre as gerações e seus efeitos; os personagens de ficção de caráter fronteiriço (ou border) do romance Border Country; pontuações que contribuam para o debate acerca dos conceitos de cultura e experiência em Raymond Williams.

PalaVRAS-ChAVE: Raymond Williams; cultura; experiência; tipo border; Sociologia da Literatura; Psicanálise.

AвSTRACT: This work, which combines literature sociology and psychoanalysis, focuses on analysing some constitutive elements of fictional narratives, such as: the temporal dimensions (past, present and future); the transmission of experiences in the family sphere; the connection between different generations and its effects; the border type fictional characters about Border Country' novel; and all that contributes to the debate on Raymond Williams' concepts of culture and experience.

1. Faculdade de Educação, Universidade Estadual de Campinas, Campinas, SP, Brasil.

2. Faculdade de Educação, Universidade Estadual de Campinas, Campinas, SP, Brasil.

3. Faculdade de Educação, Universidade Estadual de Campinas, Campinas, SP, Brasil. 
KEYWORDS: Raymond Williams; culture; experience; border type; Literature Sociology; Psychoanalysis.

\section{INTRODUÇÃO}

Raymond Williams nasceu na região rural de Pandy, aos pés das montanhas negras e diante da fronteira entre o País de Gales e a Inglaterra, no ano de 1921, e morreu em Essex, Inglaterra, em 1988, depois de se aposentar como professor de artes dramáticas na Universidade de Cambridge. Construiu uma vasta produção bibliográfica no campo da educação (mais especificamente na educação de adultos), ${ }^{4}$ da sociologia, com ênfase nos estudos de cultura, da crítica literária, e também da ficção.

Este artigo tem como objetivo analisar alguns elementos constitutivos dos seus romances não vertidos ainda para o vernáculo, como Border Country (1960), Second Generation (1964) e The Fight for Manod (1979). Nessas obras de cunho ficcional do autor está exposta, conjuntamente, uma análise das relações sociais familiares, sob o signo do problema das gerações, elas mesmas impactadas pelo dinamismo sistemático do tempo. Passado, presente e futuro estão sempre entrelaçados no interior da ficção de Williams e podem ser notados no fluxo das experiências narradas pelos personagens, sobretudo aqueles que são do tipo fronteiriço (border) e vivem no limiar de tempos e espaços que se misturam dentro deles, conforme lemos no romance Border Country.

A ênfase, portanto, deste artigo está na relação entre as dimensões temporais estabelecidas entre o passado, o presente e o futuro. O tempo é um eixo articulador no interior das obras ficcionais, condicionando as diferentes gerações que percorrem os romances, elas mesmas ligadas por experiências em comum, de onde derivam encontros e desencontros de diversos grupos sociais. Nascem disso os conflitos mais variados e são eles que tecem o todo cultural no interior das ficções, conforme lemos no excerto abaixo:

Nós estamos entediados por conta das histórias legendárias, por essas que nos foram ensinadas, mas o ritmo de tudo, da história, da vida, é tão diferente disso que nós estamos despreparados... se nós aceitarmos reduzir o nosso ritmo ao ritmo da experiência, estaremos mortos de qualquer forma, assim como as coisas agora estão (WILLIAMS, 1988a, p. 238).

4. Conferir o E-Book Raymond Williams e Educação: coletânea de textos sobre extensão, tutoria, currículo e método de ensino. Org. Alexandro Henrique Paixão. Campinas - SP: Editora da FE/Unicamp, 2019. Consulta site: http://www.bibliotecadigital.unicamp.br/document/?down=001091920. 
O que o excerto extraído do romance Second Generation está expondo é parte dessa crítica dirigida às tradições passadas, que tinham nas histórias legendárias o instrumento de comunicação de determinadas experiências entre as diferentes gerações: uma que lutou na guerra e sobreviveu, outra que era herdeira desse processo. Porque herdar é aprender com essas manifestações históricas, algo até então vital. Mas com os novos acontecimentos do mundo da vida contemporâneo - pois o romance se passa no pós-guerra -, outros condicionantes e desafios são impostos, como o sentimento de derrota.

A atmosfera ora é de não pertencimento, ora de uma dificuldade de explicar ou convencer as novas gerações existentes sobre a importância das tradições. E no instante em que as novas gerações se põem a viver determinadas situações, como enterrar o próprio pai e sentir-se mais vivo por um momento, conforme lemos no romance Border Country, novos impasses são apresentados.

Williams escreveu vários romances em inglês - Border Country (1960); Second Generation (1964); The Volunteers (1978), The Fight for Manod (1979) e Loyalties (1985). Apenas People of the Black Mountains (1989) foi traduzido para o português, como $O$ povo das montanhas negras, pela editora Companhia das Letras, em 1991.

Neste artigo, iremos apresentar alguns trechos das outras obras que ainda aguardam tradução, de modo a oferecer ao leitor brasileiro uma dimensão da variedade e grandeza da obra de Williams. Esse movimento de exposição da ficção vai nos servir, inclusive, para sustentar a hipótese de que seus escritos ficcionais mantêm um diálogo constante com sua obra não ficcional. Nos ocuparemos apenas de poucos exemplos disso, pois o foco é apresentar esquemática e parcialmente alguns elementos constitutivos de três entre seus romances, e finalizar com um estudo sobre o personagem-tipo border de Williams em Border Country.

Raymond Williams iniciou sua composição literária com a obra Border Country (1960), responsável pela caracterização da região rural do País de Gales no período entreguerras, com enfoque na relação pai e filho, na descendência de valores e na associação das gerações que convivem no espaço-tempo proposto: "ele gostava do Will, mas o via, majoritariamente, como um aspecto de Harry" (WILLIAMS, 2006, p. 286). ${ }^{5}$ Pai e filho, campo e cidade, passado e presente, tudo neste romance gira em torno das relações limítrofes ou fronteiriças das experiências compartilhadas por gerações, sendo que o que é anunciado no romance inaugural de Williams

5. Citação de Border Country que expõe as tensões entre as gerações do pai (Harry) e do filho (Will). 
perpassa outros romances do autor. Pensando nisso, podemos destacar, em passos rápidos, The Fight for Manod (1979), em que o fluxo de vida das gerações assim se desenha: "de avô e pai para filho, de John Dance para John Dance para John Dance novamente" (WILLIAMS, 1988b, p. 112). ${ }^{6}$

Nesse aspecto, Raymond Williams coloca em confronto a relação entre pai e filho como reprodução da relação entre duas gerações, pois existe a necessidade de criar experiências novas e atreladas a um tempo e espaço presentes, em contraste com as experiências das gerações anteriores, de antes da guerra.

Esta "unidade básica" de conflito entre pai e filho nos faz recordar, na verdade, aquilo que certa psicanálise apontava sobre a crítica da criança ao pai:

Deve ser que um sentimento de culpa se acha ligado à satisfação de haver ido tão longe; há algo errado nisso, algo proibido desde sempre. Tem relação com a crítica da criança ao pai, com o menosprezo que toma o lugar da superestimação infantil inicial de sua pessoa. É como se o essencial no êxito fosse chegar mais longe que o pai, e querer superá-lo ainda fosse interditado (FREUD, 2010, p. 448).

É preciso revisitar essas ideias de Freud, na medida em que Border Country é o romance que nega completamente a imago infantil da proteção paterna, necessária em tempos de mal-estar, repondo no lugar a necessidade dessa "crítica da criança ao pai", que no romance aparece nos termos de uma "superação" de Matthew em relação a Harry, algo que percorre toda a obra, cujo desfecho é a morte paterna: "pareceu como se eu estivesse tomando a vida dele. Foi isso que, no final, eu senti: eu me tornava mais forte conforme ele morria” (WILLIAMS, 2006, p. 434).

Com a morte do pai, findam também as narrativas galesas e um conjunto de experiências e vivências de um mundo pré-guerra, em que o sentimento de rural e comunidade eram decisivos. Mas como "a nostalgia é universal e persistente" (WILLIAMS, 2011b, p. 25), presente e futuro tomam sempre uma "escada rolante" de volta ao passado para provar e reprovar tal estrutura de sentimento. Nessa direção, é preciso evocar a obra não ficcional de Williams, para matizar o ponto:

Mais uma vez, porém, o que parecia ser uma eterna escada rolante, um perpétuo recuo em direção ao passado, revela-se, após um pouco de reflexão, um movimento mais

6. Raymond Williams. The Fight for Manod - tradução nossa. 
complicado: [...] todas essas coisas têm significados diferentes em épocas diferentes, colocando em questão valores bem diversos (WILLIAMS, 2011b, p. 27).

Presente e passado interagem mutuamente e se movimentam no tempo e no espaço da história, da literatura e da vida pessoal, afinal, "você é tanto a sua história e tão pouco você mesmo" (WILLIAMS, 1988a, p. 153),7 aponta Williams sobre a relação dos personagens de ficção de diferentes gerações em outro romance, Second Generation. Analisar o modo de pertencimento aos acontecimentos e às vivências de uma geração, de forma a criar uma identidade enquanto período e uma entidade capaz de interpretar os eventos de uma época à luz de seus próprios saberes é um atributo que Williams fornece aos seus personagens, com a esperança de que passado e presente combinados fertilizem um futuro, ainda que incerto ou desconhecido: "pergunte a você mesmo, agora honestamente, onde está o futuro" (WILLIAMS, 2006, p. 224), sintetiza Williams em Border Country. ${ }^{8}$

Partindo dessas ponderações, escolhemos alguns momentos nestes três romances - Border Country, Second Generation e The Fight for Manod - para indicar como um jogo entre passado, presente e futuro tece o modo de vida das gerações de galeses no tempo e no espaço da ficção retratados por Williams. Essa dinâmica e sistemática temporal podem ser compreendidas pelo fenômeno da cultura, como uma chave para conhecermos as vivências de cada geração.

E para compreender os sentidos de cultura diante do conflito geracional e como a proposição desse conflito toma forma com a problemática da transmissão de experiências entre diferentes grupos etários é preciso retomar, mais uma vez, a obra não ficcional de Williams, onde lemos:

Uma cultura tem dois aspectos: os significados e direções conhecidos, em que seus integrantes são treinados; e as novas observações e os significados que são apresentados e testados. Esses são os processos ordinários das sociedades humanas e das mentes humanas, e observamos através deles a natureza de uma cultura: que é sempre tanto tradicional quanto criativa (WILLIAMS, 2015, p. 06).

7. Raymond Williams. Second Generation - tradução nossa.

8. Raymond Williams. Border Country - tradução nossa. 
Ao pensar a cultura em sua totalidade, Williams parte da raiz da palavra, que remonta ao cultivo da terra, assim como a experiências partilhadas e incluídas dentro de toda uma organização social. Essa cultura não necessariamente nos faz aptos a participar e viver todas as experiências, mas permite que uma estrutura de sentimento seja reconhecida e legitimada por todos os envolvidos neste processo gerador do mundo da vida.

Essa concepção parte da cultura como a produção de experiências de um povo em relação à própria sociedade e à terra de forma comum entre si: "a formação de uma sociedade é a descoberta de significados e direções comuns, e seu desenvolvimento se dá no debate ativo e no seu aperfeiçoamento, sob a pressão da experiência, do contato e das invenções, inscrevendo-se na própria terra" (WILLIAMS, 2015, p. 05). A cultura é, portanto, uma produção social proporcionada pela interação dos indivíduos em sua organização como civilização, que sofre interferência de outros fatores inerentes a essa sociedade, como os sistemas de produção e de classes. Dessa forma, a cultura se distancia da experiência particular do indivíduo e configura-se como a experiência compartilhada socialmente e que se torna, portanto, comum.

Com a expansão da cultura, novas demandas e novos significados emergem, fragmentando a ideia de um grupo de indivíduos que compartilham da essência das mesmas experiências em relação ao grupo e à terra. Agora, há grupos distintos que conferem experiências também diversas ante uma cultura considerada comum: "devemos aceitar, com franqueza, que se propagarmos nossa cultura, nós a estaremos modificando" (WILLIAMS, 2015, p. 24).

Assim, o próprio conceito de cultura se divide em duas experiências distintas, uma tradicional e outra criativa, representadas por diferentes gerações. Nessa perspectiva, Williams aponta para uma cultura dividida e fragmentada, composta por grupos que não possuem uma cultura ou experiência comum. Apresenta-se o conflito a partir da quebra da ideia de cultura como uma experiência particular que se compartilha com os demais, configurando a existência de duas variantes de um mesmo modo de vida, o que leva ao conflito entre as gerações, intensificado pelo problema da comunicação, outro conceito fundamental para compreender os encontros e desencontros geracionais. 
Quando o assunto são as gerações e a questão da comunicação, necessitamos olhar para aquilo que Williams discute como o problema da linguagem. Ele nos conta que a língua, enquanto elemento mediador e comunicativo, engloba a constituição da esfera de vida dos indivíduos e compõe uma forma de experiência entre aqueles que utilizam a linguagem de modos específicos, como quando se cria narrativas inspiradas nas histórias galesas, que compõem o enredo nos romances de Williams. Reconhecidas pelos personagens como objetos simbólicos que entrelaçam gerações, as histórias lendárias não operam somente a transmissão de experiências entre os grupos; elas mesmas refratam o conflito geracional em sua forma literária, porque se escolhe narrar determinada estrutura de sentimento tradicional do passado não pela forma do romance e sua epopeia burguesa, mas pelos mitos e narrativas populares expressos nas lendas.

Rejeitando uma forma literária específica, como as lendas, refuta-se também um padrão cultural linguístico outrora estabelecido pelas tradições galesas no interior de uma mesma comunidade. $E$ uma vez rompida determinadas experiências narrativas, suprime-se também uma parte vital dessa mesma experiência, algo que impacta seu devir.

É dessa condição que nascem as perdas e as ameaças à linguagem: "a linguagem perdeu decisivamente, no caso, sua definição como atividade constitutiva" (WILLIAMS, 1979, p. 38). Ela passa a estabelecer apenas formas de utilização para comunicar experiências do passado, não para tecê-las ou recriar novos mundos no presente rumo ao futuro. Quebrando esse fluxo, rompe-se o processo complexo de comunicação, ou seja, de transmissão, recepção e resposta (WILLIAMS, 1978), algo necessário para compartilharmos experiências em comum, sendo que o binômio comunidade e comunicação pode reter e traduzir, podemos aventar, todo esse processo. ${ }^{9}$

Dessa forma, comunicar significados em comum faz parte da realização da cultura, do modo de vida de diferentes gerações humanas encarnadas no grupo social mais elementar e conhecido: a família. A família se constitui como uma instituição inicial de inserção na cultura, sendo a primeira constelação social conhecida pelo indivíduo em sua vida, algo modelador de uma moral e reprodutor de uma cultura comum:

9. Sobre comunicação e comunidade na perspectiva de Williams, conferir o segundo ensaio, "Comunicações e Comunidade" (1961), do livro Recursos da Esperança, publicado pela editora Unesp, em 2015. 
Se fosse inteiramente verdade que a criação de significados é uma atividade da qual participam todos os homens, certamente ficar-se-ia horrorizado com qualquer sociedade que em sua cultura mais explícita ou suprimisse os significados e os valores de grupos inteiros, ou deixasse de estender a esses grupos a possibilidade de articular e comunicar esses significados. (WILLIAMS, 2015, p. 53)

A transmissão da experiência, passando pelo processo de comunicação, precisa ser recebida, interpretada e organizada (apropriada) por aquele que vai recebê-la. Portanto, a experiência também pode ser ignorada ou rejeitada nesse processo de transmissão. Diante desse impasse deve-se pensar de que maneira a experiência alcança seu ouvinte e sob quais efeitos. A recepção e resposta ativa dependem de uma comunidade de experiência eficiente, as chamadas "comunidades cognoscíveis", de que fala Williams em O Campo e a Cidade, porque a palavra ativa, aquela que quebra o silêncio, restaura a comunicação e o diálogo entre as gerações. Mas havendo o silêncio abdica-se da linguagem? Na verdade, não. Apesar de o silêncio ser sentido muitas vezes como uma violência da linguagem, a palavra não está ausente, mas suspensa, presa. $\mathrm{O}$ que significa que existe linguagem no silêncio, uma verdadeira comunidade de experiências em movimento, só que reflexas, indiretas e galvanizadas "sob a pele das palavras...."

Para compreender um pouco melhor essa atmosfera de esconderijos da obra de Williams precisamos conhecer seu personagem do tipo border. Ele é quem sofre com o silêncio de palavras e sente-se no limiar das coisas ditas e não ditas. E onde não ocorre comunicação podem imperar as situações ambivalentes, um real mal-estar.

Frente a isso, Williams cria um tipo ficcional fronteiriço, que paira entre o luto e o triunfo, algo gerador de um ambiente conflituoso, cuja moldura é preenchida pela necessidade de superação das tradições existentes.

O conflito, na verdade, deve-se a sentimentos “ambivalentes”, conforme anuncia Freud, guardadas as devidas proporções, no ensaio "Inibições, sintomas e ansiedade”, datado de 1926. Contudo, precisamos combinar as teses de Freud com uma outra tradição psicanalítica, haja vista que a ambivalência aqui só cria um universo de sentido quando associada às posições maníaco-depressivas de que trata Melaine

10. A referência a uma parte do verso de Carlos Drummond de Andrade, no poema "A flor e a náusea" ( $A$ rosa do povo), é bem-vinda na medida em que o sentimento de triunfo que apresenta o personagem border de Williams, que ainda iremos estudar, não alça ao caráter sublime de uma flor, em razão de seu conteúdo nauseante, ele mesmo perturbador, e gerador de uma imago ambivalente na ficção de Border Country. 
Klein, em 1940, no ensaio "Luto e suas relações com os estados maníaco-depressivos”. Ambivalência e depressão são dois pares, portanto, necessários para se pensar os estados maníaco-depressivos de personagens fronteiriços, como aquele criado por Williams em Border Country.

$O$ trecho que nos interessa nesse romance já foi indicado aqui, mas será preciso retomá-lo por conta do seu caráter triunfante e dramático, um verdadeiro "drama em cena", onde pai e filho se encontram diante do leito de morte. "Pareceu como se eu estivesse tomando a vida dele. Foi isso que, no final, eu senti: eu me tornava mais forte conforme ele morria" (WILLIAMS, 2006, p. 434), " comenta Matthew diante do moribundo Harry. Essa relativa vitória frente ao pai não passa, na verdade, de uma defesa maníaca frente a estados depressivos. Segundo Klein, sentimentos tanto destrutivos quanto reparadores, ambivalentes portanto, decorrem de uma onipotência maníaca, de controlar o perigo ou de deixá-lo em suspensão. Esse triunfo ligado ao desprezo e à onipotência, para ela, é um elemento constitutivo da posição maníaca. O problema é que o triunfo do sujeito sobre seus objetos tem sempre um limite, gerando no fim das contas sentimentos de perseguição ou mesmo avaliações exageradas sobre a vida e as coisas, que é algo que sentimos em pessoas enlutadas, como o personagem Matthew Price de Border Country.

Border Country é uma narrativa apoiada na estrutura de flashbacks, numa espécie de vórtice entre o presente do personagem Matthew, codinome Will, e o passado de seu pai, Harry Price, personagem que recebeu o primeiro nome do pai do próprio Raymond Williams. O romance envolve um arco temporal dos anos de 1920 a 1950, trazendo fatos históricos como a greve geral de 1926, o desenvolvimento do Partido dos Trabalhadores, o impacto da crise de 1929, o início das tensões relacionadas ao fascismo e as consequências das duas Grandes Guerras Mundiais. Combina-se a esses fatos históricos narrados um sentimento de nação muito forte e contraditório, pois o romance se passa na região fronteiriça do País de Gales com a Inglaterra, nas suas bordas, fazendo com que o personagem transite entre os dois polos regionais a todo momento. Tanto que a narrativa se inicia com o retorno de Matthew Price de Londres, que trabalha como renomado professor e pesquisador em economia e que deixou o trabalho, a capital e a família, por um curto período, para visitar o pai enfermo na cidade natal de Glynmawr.

11. Raymond Williams. Border Country - tradução nossa. 
A chegada, o encontro com os entes familiares e com a vida na comunidade produzem no personagem um profundo sentimento de perda, tanto que Matthew desabafa: "eu estive longe por muito tempo. Eu esqueci tudo e não consigo me trazer de volta" (WILLIAMS, 2006, p. 98). ${ }^{12}$ Esse sentimento de distância e cancelamento da memória, somado à impossibilidade de não se sentir capaz de voltar, geram, primeiro, uma atmosfera ansiosa no personagem no interior da narrativa, que se transfigura numa atitude destrutiva e depressiva ao mesmo tempo, enquanto assiste ao definhamento paterno.

O tom é fúnebre, emoldurado por um sentimento ambíguo de perda e reconquista da vida, pois enquanto um morre, outro renasce. Ao sugar toda a vida moribunda de seu pai em seu leito de morte, Matthew estaria, numa primeira leitura, enfrentando a morte e lutando pela sua sobrevivência, buscando força e vigor naquele momento em que uma vida se esvai. Todavia, essa passagem nos revela um sentimento bastante agressivo de Matthew em relação ao seu pai, na medida em que a vida depende do sepultamento do universo paterno, consequentemente, da sua autoridade e família. Estamos diante de uma posição bastante fronteiriça entre Matthew e Harry.

A fronteira que antes dividia o País de Gales e a Inglaterra agora dividia emocionalmente o personagem, que se deprime com a volta para casa paterna, com a morte do pai, ao mesmo tempo em que é tomado por um sentimento muito forte de dor na tentativa de se preservar, de sobreviver. Mas, ao tentar se desligar completamente do pai, cancela o sentimento de perda, de tristeza e, portanto, de gratidão, repondo no lugar um sentimento de derrota em relação ao passado, conforme lemos em Border Country:

É possível falar sobre criar o futuro, mas na prática as pessoas correram por abrigo, articuladas para a conveniência pessoal, aceitaram os fatos do poder existente. Ver isso acontecer foi uma grande perda de esperança, um devagar e chocante cancelamento do futuro... (WILLIAMS, 2006, p. 190).13

A fronteira que existia entre o País de Gales e a Inglaterra agora se apresenta na fala e no interior do personagem, que se divide emocionalmente para assistir, de um lado, o pai em seu leito de morte, e de outro, a cidade, o povo, a nação, que, apesar

12. Raymond Williams. Border Country - tradução nossa.

13. Raymond Williams. Border Country - tradução nossa. 
de ter vencido e sobrevivido às duas grandes guerras mundiais e tantas outras crises, é derrotada pela falta de futuro.

Enfim, tudo nesse personagem se organiza em termos de vulneráveis fronteiras espaciais e/ou emocionais, revelando a dor, o amor, o ódio e a desesperança. Todavia, não são os sentimentos ambivalentes que ficam à mostra para o leitor; antes, é o triunfo do personagem o que se destaca na cena. Contudo, já sabemos que essa vitória é encobridora de estados maníaco-depressivos e da dificuldade do personagem de ultrapassar as fronteiras da vida. "Conflitos dessa natureza devido à ambivalência são muito frequentes e podem ter outro resultado típico", comenta Freud (FREUD, 1996, p. 106). Esses resultados típicos são os estados delirantes e maníaco-depressivos, tal qual vimos em Klein, em que a ambivalência surge nas situações em que se tenta reparar aquilo que foi perdido ou ameaçado, tentando triunfar frente aos ataques de objetos maus ou terríveis, sendo esses os próprios personagens, como no caso da cidade ou do pai de Matthew Price.

A ambivalência, assim, seria a prova dos aspectos fronteiriços do nosso personagem-tipo, pois coexistem nele o amor e o ódio manifestos nos sentimentos de triunfo sobre a morte. Personagens fronteiriças, portanto, não são autoritárias, mas podem ser delirantes, maníacas e depressivas, pois se sentem triunfando sobre uma vida que está sempre à beira de um colapso, como a perda da esperança no porvir. Esse medo do colapso é sentido de várias formas e identificado em diferentes objetos, como numa figura paterna, o que pode pressionar ou ameaçar a segurança de toda uma simples e vulnerável existência.

Quando observamos certo personagem de ficção de Williams, ele mesmo fronteiriço e ambivalente, sentimos, pois, uma forte presença de um conflito de comunicação entre ele mesmo e seu respectivo ambiente. Tais conflitos apresentados têm o rosto de uma crise, uma crise dos colapsos humanos frente às relações familiares ou simplesmente os dilemas e desafios de uma vida solitária, errante pelos abismos existentes na sociedade contemporânea. São situações e sintomas, na verdade, muito simples e ordinários que Williams nos apresentou através desse personagem fronteiriço.

Conflitos entre pai e filho não passam de dilemas e dores comuns que todos os homens enfrentam em sociedade, e é isso que a ficção de Williams quer nos apresentar: a gravidade das coisas simples ou ordinárias e complicadas da vida contemporânea que necessitam vir à tona novamente para que a comunicação seja restabelecida nas situações mais individuais. $\mathrm{O}$ que era central e essencial para $\mathrm{o}$ autor galês era oferecer uma expressão mais humana da vida em sociedade, sem a 
qual seu personagem principal perderia sua significação naquele tempo. Esse captar de conflitos simplesmente existenciais é a forma que Williams encontra para repor aquilo que ficou ameaçado com a Segunda Guerra Mundial: a comunicação de coisas comuns, ordinárias, como sentimentos ambivalentes que habitam todos os seres humanos viventes, conforme vimos em passos rápidos no exemplo de Will, codinome de Matthew Price, personagem principal de Border Country.

E onde as imagos são ambivalentes impera o conflito, consequentemente, atos de violência de corpos e mentes cindidos ante a impossibilidade de se comunicar efetivamente, pois o sentimento de triunfo e dor galvaniza as situações familiares, impedindo que o vórtice das relações parentais se realize enquanto situação ordinária ou comum, porque a cultura é algo comum e não, necessariamente, um constante mal-estar.

\section{O FLUXO DE EXPERIÊNCIAS NOS ROMANCES DE WILLIAMS}

O primeiro romance de Williams é uma introdução a uma narrativa que se mantém ao longo de suas demais obras literárias no sentido de construir uma inter-relação entre cultura, geração e experiência, tendo sido a ênfase deste artigo discutir essa relação e seus significados.

Não houve espaço para debatermos os outros romances, mas não queríamos deixar de dizer que a proposição que nos guia é que Border Country e os demais romances escritos por Williams colocam em cena uma determinada estrutura de sentimento: o conflito entre as gerações. Nesse sentido, as obras vão, gradualmente, apresentando ao leitor o seu foco central na transmissão de experiências entre as gerações, cada obra desenvolvendo e acrescentando um novo aspecto essencial à compreensão desse modo de vida comum aos três romances citados: o fluxo de experiências geracionais e as discussões a ele agregadas.

É pela comunicação que os valores, experiências e significados são transmitidos de uma geração a outra, garantindo a manutenção da unidade cultural, assim como de uma ordem social. Segundo Williams, a comunicação é um processo que acontece entre membros de uma sociedade que compartilham de uma cultura comum, isto é, indivíduos que em sua particularidade compartilham experiências comuns. Dessa forma, se não há este encontro entre os indivíduos através de um movimento no qual haja transmissão, recepção e resposta, não há comunicação. A partir disso, Williams aponta, também, para a comunicação como um processo essencial e intrínseco às 
sociedades. Comunicação é, portanto, a vereda pela qual se estabelece a prática social específica de cada comunidade/sociedade, configurando-se enquanto cultura.

É possível compreender que, de acordo com as definições de Williams, a cultura depende integralmente da comunicação, pois é necessário que os membros da sociedade consigam se comunicar a ponto de compartilhar experiências, descobrimentos e aprendizados, e de forma a manter a cultura viva através das gerações, que devem compartilhar dessa mesma cultura inicialmente proposta pelas gerações antigas e tradicionais, conforme vimos nos romances estudados.

O processo de comunicação é acompanhado por outros movimentos descritos por Williams, sendo um dos principais a ação de descrever. Nesse sentido, o autor aponta para o ato descritivo, classificando-o a partir da ideia de que "[...] a experiência tem de ser descrita para poder ser realizada (essa descrição sendo, na verdade, colocar a experiência em uma forma comunicável)" (WILLIAMS, 1984, p. 43). ${ }^{14}$ A partir disso, a comunicação se consolida como um aspecto necessário tanto à manutenção da cultura quanto, e intrinsecamente, ao aprendizado e às descobertas realizadas diante da prática social. Williams retoma, ainda, a importância da comunicação como consolidação tanto do aprendizado como dessa cultura em constante construção.

É nessa relação entre cultura e comunicação que se estabelece uma crise relativa aos papéis culturais das gerações diante do conhecimento, assim como sua obtenção e repercussão. Partindo da concepção de uma cultura comum, Williams aponta para a existência de dois aspectos de uma mesma sociedade, um primeiro movimento tradicional e um segundo criativo, apontando em direção a uma crise de comunicação entre eles. Desdobra-se disso o argumento de que existem duas formas de experiências vividas pelos homens: uma primeira baseada na própria mentalidade do indivíduo; outra baseada em interpretações relativas à cultura, sendo que ambas são formas de interpretar o mundo.

A cultura comum é uma forma de imitação, enquanto a cultura que é experimentada, criada e desenvolvida através de um novo modo de vida é tida como o crescimento de um grupo social criativo. São dessas diferenças de perspectivas que emergem o conflito de ideias entre as gerações, algo intensificado pela crise de comunicação entre as partes de uma mesma sociedade, que compartilha ora uma cultura comum de ordem mais tradicional, ora uma cultura criativa, conforme lemos em Border Country, mas também em Second Generation e The Fight for Manod.

14. Raymond Williams. The Long Revolution - tradução nossa. 
À guisa de conclusão, pode-se afirmar que foi necessário interpretar as narrativas dos romances, que abordam temáticas como a relação entre pai e filho, assim como a relação com a terra e o conflito das diversas fronteiras (tanto físicas como metafóricas), elegendo como foco narrativo no romance Border Country o personagem de ficção de caráter fronteiriço Matthew Price. Graças a ele, foi possível refletir sobre como uma cultura comum foi sendo superada pelas novas gerações triunfantes, na medida em que Will põe em cena os significados do povo de Glynmawr e a relação com seu pai, consequentemente com seu avô e também com seus filhos. Todavia, sendo essa operação um estado ambivalente e doloroso de viver a vida, o triunfo de Will não supera a morte paterna, nem repõe as experiências em comum aprendidas. Antes, galvaniza com dor a sensação de perda e se enche de orgulho e glória, por sentir que o passado estava sendo enterrado com seu pai. Mas o que Will não percebe é que viver e reviver em uma terra criada por uma geração anterior é não abrir mão das tradições, sem as quais presente e futuro não se realizam, no sentido de experiências compartilhadas e também processuais.

O que o personagem principal de Border Country desconhecia é que os estados maníaco-depressivos são frequentes naqueles que se sentem triunfando sobre a vida. Mas isso não passa de um grande mal-estar, pois uma cultura em comum não se constrói com sentimentos vitoriosos, mas com experiências de perdas e derrotas. A história de uma cultura em comum é a história dos vencidos e não dos vencedores. Williams nos contou isso inúmeras vezes em seus textos não ficcionais, como no ensaio A cultura éalgo comum, de 1958. Aqui, em Border Country, ele novamente lança luz sobre esse problema, dessa vez criando um personagem fronteiriço, que é um verdadeiro testemunho de que a luta contra o mal-estar na civilização pode ser iniciada reconhecendo e valorizando as experiências mais ordinárias e conflituosas da vida, tudo aquilo que ocorre no todo e na parte das constelações humanas mais diversas.

\section{REFERÊNCIAS}

BENJAMIN, Walter. Magia e técnica, arte e política: ensaios sobre literatura e história da cultura.

Tradução de Sergio Paulo Rouanet. 7. ed. São Paulo, SP: Brasiliense, 1994.

CEVASCO, Maria Elisa. Para ler Raymond Williams. São Paulo: Paz e Terra, 2001. . Dez lições sobre estudos culturais. São Paulo: Boitempo, 2003.

GLASER, André. Raymond Williams: materialismo cultural. São Paulo: Biblioteca 24 horas, 2011. 
FREUD, Sigmund. Um distúrbio de memória na Acrópole. In: . O mal-estar na civilização, novas conferências introdutórias à psicanálise e outros textos (1930-1936). São Paulo: Companhia das Letras, 2010. . Inibições, Sintomas e Ansiedade (1926). In: . Um Estudo Autobiográfico, Inibições, Sintomas e Ansiedade, Análise Leiga e outros trabalhos (1925-1926). Volume XX. Rio de Janeiro: Imago, 1996.

KLEIN, Melanie. Luto e suas relações com os estados maníaco-depressivos. In: . Amor, culpa e reparação. Imago: Rio de Janeiro, 1996.

MANNHEIM, Karl. O problema sociológico das gerações. In: FORACCHI, Marialice. M. Karl Mannheim: sociologia. São Paulo: Ática, 1982.

SMITH, Dai. Raymond Williams: a warrior's tale. Llandysul: Parthian, 2008.

WILLIAMS, Raymond. (1948). Lectura y crítica. [s.l.]: Ediciones Godot, 2013. . (1958). Cultura e Sociedade: de Coleridge a Orwell. Tradução de Vera Joscelyne. Petrópolis,

RJ: Vozes, 2011.

. (1960). Border Country. Cardigan: Parthian, 2006. . (1961). The Long Revolution. Cardigan: Parthian, 1984. . (1964). Second Generation. London: The Hogarth Press, 1988a. . (1966). Los Médios de Comunicación Social. Barcelona: Península, 1978. . (1973). O campo e a cidade na história e na literatura. Tradução de Paulo Henriques Britto.

São Paulo: Companhia de Bolso, 2011. . (1978). The Volunteers. Cardigan: Parthian, 2011. . (1979). A Política e as Letras. Tradução de André Glaser. São Paulo: Editora Unesp, 2013. . (1979). Marxismo e literatura. Tradução de Rio de Janeiro, RJ: Zahar, 1979. . (1979). The Fight for Manod. London: The Hogarth Press, 1988b. . (1985). Loyalties. London: Chatto \& Windus, 1985. . (1989). Recursos da esperança: cultura, democracia, socialismo. Tradução de Nair Fonseca.

São Paulo, SP: Editora UNESP, 2015.

\section{SOBRe OS AUTORES}

Alexandro Henrique Paixão é professor de Sociologia da área de Pensamento Social e Educação, do Departamento de Ciências Sociais na Educação e Programa de Pós-Graduação em Educação, Faculdade de Educação, Universidade Estadual de Campinas. Graduação em Ciências Sociais, Universidade Estadual Paulista Júlio de Mesquita Filho (Unesp: 1998-2001); Mestrado em Sociologia, Universidade de São Paulo (USP: 2003-2005); Doutorado em Sociologia, Universidade de São Paulo (USP: 2008-2012), com estágio de pesquisa na Université de Versailles Saint-Quentin-en-Yvelines (2010-2011); Pós-doutorado em Teoria e História Literária, Universidade Estadual de Campinas (Unicamp: 
2013-2014); Formação em Psicoterapia Psicanalítica, Centro de Formação e Assistência à Saúde Mental (Cefas: 2018-2019). Coordenador do Laboratório de Estudos de Cultura, História, Educação e Sociologia (LECHES) e do Projeto Raymond Williams e Donald Winnicott: sobre formar e cuidar de sobreviventes. E-mail: ahpaixao@gmail.com.

José Ricardo Beltramini de Melo é mestrando no Programa de Pós-graduação da Faculdade de Educação/Unicamp na linha de Educação e História Cultural sob a orientação do Prof. Dr. Alexandro Henrique Paixão. Graduado em Ciências Sociais pelo IFCH - Unicamp na modalidade de Bacharel - Sociologia e Licenciatura. Foi membro do Programa Institucional de Bolsa de Iniciação à Docência (PIBID)subprojeto História entre 2015-2017. Atualmente é integrante do Laboratório de Estudos de Cultura, História, Educação e Sociologia (LECHES).

E-mail: jrbeltramini@hotmail.com.

Mariana Carvalho Murad é graduanda em Pedagogia (Universidade Estadual de Campinas). É pesquisadora-membro do Laboratório de Estudos de Cultura, História, Educação e Sociologiada (LECHES) da Universidade Estadual de Campinas. Tem experiência na área de estudos culturais e literaura, com pesquisa no seguinte tema: romances de Raymond Williams, financiada pela FAPESP nos anos de 2018 e 2019.

E-mail: marianacmurad@gmail.com.

Recebido em o1 de julho de 2019 e aprovado em 23 de setembro de 2019. 